\title{
Developing a Chaotic-Simulation Based Model for Ranking High Selected Network Links in Hazardous Material Transportation
}

\author{
Abbas Mahmoudabadi \\ Department of Engineering, Payame Noor University, Shahnaz Alley, Nourian Street, North Dibagi Avenue, Tehran, Iran \\ Correspondence should be addressed to Abbas Mahmoudabadi; mahmoudabadi@phd.pnu.ac.ir
}

Received 17 July 2013; Revised 20 February 2014; Accepted 21 February 2014; Published 7 April 2014

Academic Editor: Ligang Wu

Copyright ( 2014 Abbas Mahmoudabadi. This is an open access article distributed under the Creative Commons Attribution License, which permits unrestricted use, distribution, and reproduction in any medium, provided the original work is properly cited.

Hazardous material transportation is one of the main concerns due to the nature of hazardous materials and their incident impacts. In general, transport risk is a main attribute to develop mathematical models for hazardous material routing problem as well as network designing or improving road safety. This paper presents a chaotic-simulation based model to determine the high selected links to improve road network quality for hazardous material transportation, in which risk is considered as a chaotic variable over the network whereas a simulation technique has been applied to cover a wide range of selecting paths. A real road network, consists of fifty-nine nodes and eighty two-way edges, is used for running the mathematical model and checking validation. Due to the large amounts of hazardous material transported by trucks, the proposed methodology is focused on fuel transportation, and high selected list of edges (links) has been obtained to improve road safety. Sensitivity analysis revealed that using different seeds for generating transport risk has no significant effects on finding the most frequent paths and high selected edges.

\section{Introduction}

1.1. Hazmat Routing Problem. Hazardous materials (hazmat for short) are classified into nine classes of explosives, gases, flammable liquids, flammable solids, oxidizing substances, toxic substances, radioactive materials, corrosive substances, and miscellaneous dangerous goods [1]. Hazardous materials transportation covers a significant part of the economic activities in industrialized countries, so management of hazardous material is an extremely complex issue involving a multitude of environmental, engineering, economic, social, and political concerns $[2,3]$. One of the most important issues in this area is to find the best path for transporting hazardous materials. Determining the route for hazardous materials, hazmat routing problem, is usually known as a two-sided consideration problem, in which the local authorities are interested in minimizing public risk and transport companies or carriers are concerned about minimizing transport cost [4]. Therefore, a combination of risk and cost is observed in mathematical models as a usual way to find the best path which is not necessarily as the shortest path. Different combinations of risk and cost priorities lead researchers to use different methods for solving hazmat routing problem $[5,6]$.

1.2. Computer Simulation. Computer simulation is a technique in which a real-life or hypothetical situation is modeled on a computer to see how the system works [7]. According to studies observed in the literature, simulation is wellaccepted technique in engineering science, because it is generally cheaper and safer than conducting experiments with a prototype of the final product, is more realistic than traditional experiments, is often to be conducted faster than real time, and allows for integration of simulated systems in the early analysis phase [8]. In the field of traffic and transportation, using computers for simulating traffic volume is found to be useful to study traffic situation and drivers behavior in a prespecified network and traffic assignment [9]. It is also applied in the field of road safety particularly in road safety assessment [10], studying the effects of incidents on road safety [11] and estimating the performances of vehicles' intelligent speed adaptation systems on pedestrian safety [12]. Using simulation modeling in the case of traffic incidents 
is another example which helps designers to determine the best locations for installing fire extinguishers equipment [11]. Simulation approach is also utilized to analyze the performance of road equipment designing on roads [13] and may be a good tool for making tactical and strategic planning [14]. Combining simulation and optimization techniques in the process of decision making and management [15], rural road network management [16], and selection and construction problem [17] is also found in the literature, which is the basis of the conceptual framework of procedure followed in this research work.

1.3. Chaos Theory. Edward Lorenz introduced the concept of chaos theory in 1963 . He found the chaotic attractions in complex systems of weather forecasting when he entered different values as starting points in computer program [18]. Some sudden and dramatic changes in nonlinear systems may give rise to the complex behavior called chaos [19]. Chaos has been studied within the engineering scientific and mathematical communities and found to be useful in many disciplines such as high-performance circuits and devices, collapse prevention of power systems, and also information processing [20]. Since chaos theory is used to analyze complex systems and transportation systems are complex entities, it is useful for transportation applications. In transportation systems, legal and social constraints may bind behavior, allowing researchers to more accurately predict human actions and system evolution [21, 22]. Regarding this area, Mahmoudabadi and Seyedhosseini $[23,24]$ approved that the behavior of road accidents over the road network is chaotic and showed that the ratio of the fatal accidents in a part of network to accidents all over the network has chaotic behavior and can be defined as a chaos factor. They used the normal form of logistic equation [19] to generate dynamic risk factors over a year and applied the concept of chaos theory to define dynamic risk factors in two research works in which the Lyapunov characteristic exponent was evaluated for checking the presence of chaos [25].

1.4. Vision. The specified road network is usually determined by national and/or local authorities to minimize risk for hazardous material transportation [4], and trade-off between effective attributes plays significant roles in finding paths for hazmat transportation. Therefore, using a wide range of dynamic risk factors in hazmat routing problem could be a practical concern on improving road safety measures over a road network. This concern will become more serious when a huge portion of goods, categorized as hazardous material, are carried annually. On the other hand, the budget constraints make decision makers apply more accurate methods for improving road safety in particular on the road network specified for hazmat transportation. The aim of this paper is to achieve a high selected (ranked) list of edges used for hazmat transportation in which road accidents associated with the specified network are considered to be a chaotic variable. A two-level iterative procedure is proposed in which the first step is to consider the chaotic behavior of road accidents as network risk and in the second step a simulation technique is provided to cover a wide range of risk factor variations.

In brief, since hazmat transport risk can be defined as a chaos factor [23], a procedure has been proposed for ranking selected network edges to improve their constructive situation. It is considered that accident risk is a chaotic factor in road safety planning and used the property of simulation technique in the proposed procedure. An iterative approach has also been developed to cover a wide range of risk and cost priorities and number of iterations corresponding to using chaos theory [24] and satisfying simulation property of running the model in specified iterations.

This paper is articulated in seven sections. After introduction, which consists of some brief descriptions on hazmat routing problem, simulation, and chaos theory; more details on the problem will be discussed at the next section. A proper methodology including setting parameters and defining loops to consider the fundamental of simulation technique and chaos theory is developed, followed by developing mathematical model to consider risk and cost priorities. Numerical studies are discussed in the sixth section using five different scenarios in terms of risk and cost priorities. Eventually summary and conclusion are presented in the seventh section.

\section{Problem Definition}

Fuel, the third type of hazardous materials recognized as flammable liquids, is one of the most important substances which are carried to the purposes of home warming, industries, private cars, and agricultural facilities. Carrying fuels from main distribution centers through heavy trucks to demand points is the usual mode of transportation. In the case of predefined points of demands which are usually defined according to the population and geographical characteristics of inhabited points, road improvement programs should be planned regarding the minimization of transport risk and transport cost, simultaneously. Therefore, the main concern of local or national authorities is to determine suitable paths for carrying hazardous materials in terms of risk and cost. The risk of hazmat transportation is mainly associated with accidents occurring in road network and population who inhabited near the roads. It also includes the environmental concerns and represents the effects on natural resources such as rivers, lakes, and trees and heavy damages to vital infrastructures such as tunnels and bridges [24].

The main question, here, is that "Which edges, determined for hazardous material transportation in terms of the risk and cost of hazmat transportation, should be prioritized to improve hazmat transport safety?" In this case, a prioritized list of edges is required to improve network safety regarding a wide variation of risk and cost priorities which may be dictated by national and/or local authorities.

\section{Defining Methodology}

According to the problem definition and simulation process as well as chaotic behavior of road accidents, the proposed 


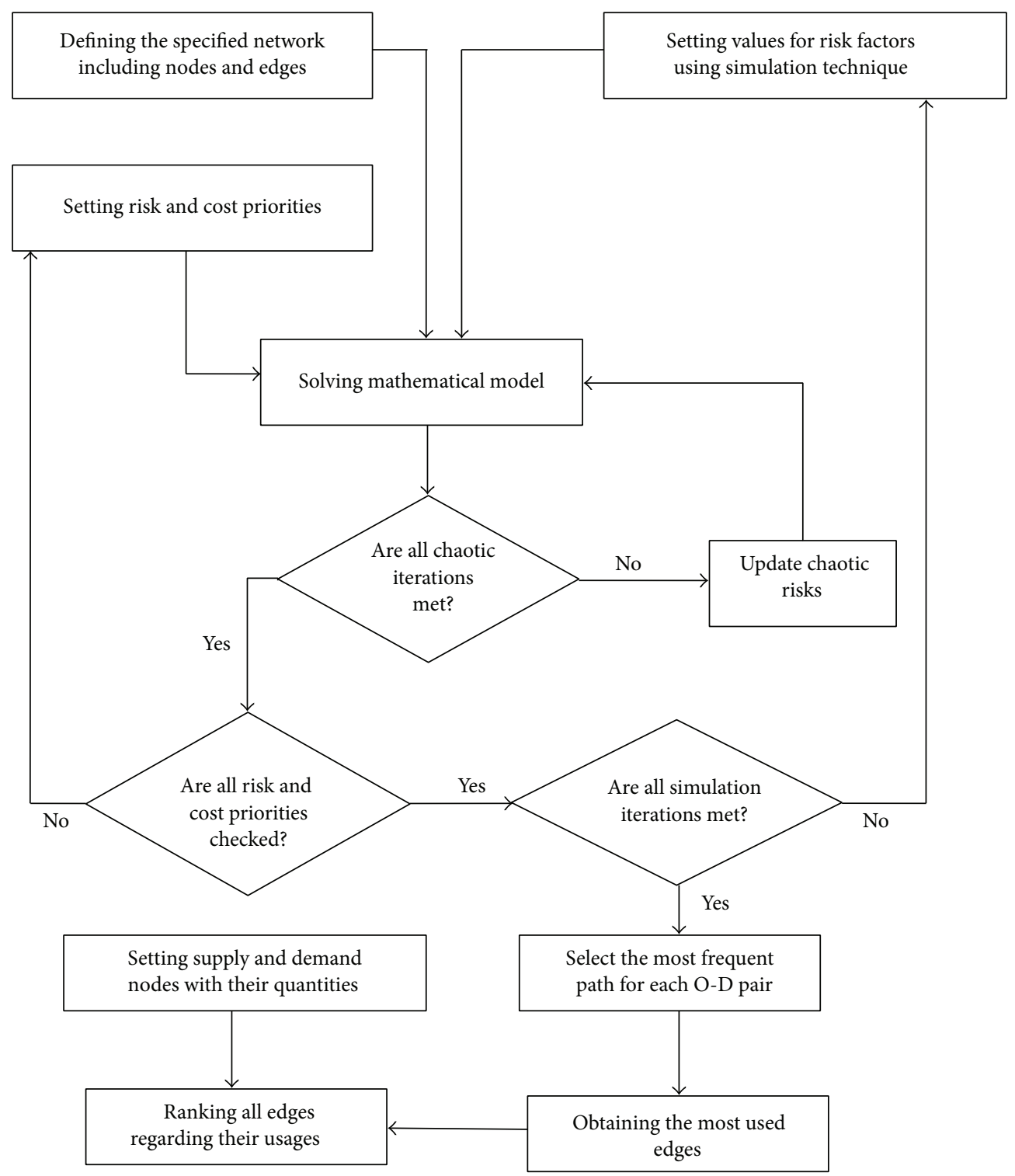

FIGURE 1: An overall view of the proposed methodology.

methodology is an iterative based procedure. A two-level iterative procedure is developed to consider simulation technique, chaotic behavior of road accidents, and hazmat incidents' impacts. The external loop is to consider initial risk factors associated with edges of the specified network, while the internal loop is developed according to selecting the most frequent paths for all O-D pairs of supplies and demands.

If the dimensions of variables are different, the scales of variables affect on results, so variables should be uniformed to reach to the reliable results [24]. Because of existing different scales of variables [24] (1) is used to uniform variables into closed interval [0.05 0.95], where $X_{\text {new }}$ is uniform amount of variable $X_{\text {old }}$ and $X_{\max }$ and $X_{\min }$ are the maximum and minimum values of variable $X$, respectively. Consider

$$
X_{\text {new }}=\frac{\left(X_{\text {old }}-X_{\text {min }}\right)}{\left(X_{\text {max }}-X_{\text {min }}\right)} \times 0.9+0.05 \text {. }
$$

When the most frequent path is determined for each O-D pair, all supplies and demands are assigned to the network. Eventually, the number of trucks assigned to all edges will be determined and they are ranked according to their usages in hazmat transportation. Figure 1 also shows the overall view of proposed procedure which includes the steps below:

(1) define the specified network, nodes, and edges;

(2) set supply and demand nodes as well as their quantities to build the matrix of O-D pairs;

(3) set initial values for risk factors of all edges in the network;

(4) calculate the uniform risk and cost values to reach variables' homogeneity;

(5) set risk and cost priorities dictated by national and/or local authorities; 
(6) solve the proposed mathematical model to determine risk-cost combination factors of the best path for O-D pairs;

(7) if the number of interior iterations is not met, update chaotic risk factors and go back to step 6;

(8) if all different risk and cost priorities are not checked, go back to step 5;

(9) if the number of external iterations is not checked, go back to step 5;

(10) obtain the most frequent paths for all O-D pairs;

(11) determine high selected list of edges in terms of their usages in order to prioritize road safety measures.

\section{Developing Mathematical Model}

Finding path is the most important step in the proposed procedure. Assume that road network is defined by graph $G(n, e)$ including predefined nodes and edges. Nodes are categorized into three main sets including destination nodes, origin nodes, and connecting nodes. Destination nodes may be also origin nodes, so the cost between the same nodes will be automatically set to zero. Following the strategy defined in the previous section, mathematical model should be developed to minimize the total combination of risk and cost over the network. The best path will be obtained in terms of combined risk and cost priorities followed by determining the amount of hazmat which should be carried from each origin to the correspondent destinations.

It is assumed that the amount of hazmat which should be transported from all origins to destinations is specified. For each origin-destination pair, the most frequent path will be outlined, so the objective function is defined by (2) as follows:

$$
\begin{gathered}
\mathrm{CR}_{o d}=\text { the most frequent path for O-D in which } \\
\operatorname{Min} Z(\text { it })=\sum_{G}\left[P_{r} \times R_{i j} \text { (it) }+P_{c} \times C_{i j}\right] \times X_{i j} \\
\forall \forall o d \in(\mathrm{O}-\mathrm{D}) \text { Pairs, }
\end{gathered}
$$

it $=2,3, \ldots$, number of chaos iterations,

where $\mathrm{CR}_{o d}$ is the best path determined by considering the combination of risk and cost obtained by determining the safest path between origin node " $o$ " and destination node " $d$ " in which the total combination of risk and cost for selected path is considered as criterion. While symbol (it) donates the chaos iteration number, $P_{r}$ and $P_{c}$ are the priorities of risk and cost, respectively. Since the model has been developed using parametric variables of priorities, decision makers can use different amount of priorities to consider different visions. In this case, if decision makers want to generalize the model for transporting the other goods, they just need to set risk priority to zero (0). $R_{i j}$ is the uniformed transport risk for edge $(i, j), C_{i j}$ is uniformed transportation cost for edge $(i, j)$, and both are derived by (1). Risk is updated using the concept of chaos theory (logistic map equation) in each chaotic iteration, while it is initialized by a random variable in simulation process. Therefore, two internal and external loops have been developed. The external loop in the model has been constructed considering simulation process and the internal loop has been constructed considering chaotic one. $R_{i j}$ is also updated using a well-known equation of generating chaotic patterns [24] named logistic map equation applied by (3) in which parameter $K$ is set as 4 [20]. Consider

$$
\begin{gathered}
R_{i j}(\mathrm{it})=K \times R_{i j}(\mathrm{it}-1) \times\left(1-R_{i j}(\mathrm{it}-1)\right) \\
\forall \mathrm{it}=2,3, \ldots, \text { number of chaos iteratins. }
\end{gathered}
$$

$X_{i j}$ is a binary variable which will be set to 1 if edge $(i, j)$ is located in determined path, otherwise it will be assigned by 0 . The uniformed amounts of risk and cost are used due to existing different dimensions for risk and cost [23]. In order to keep continuous path, (4) is considered in the mathematical model [26]. Consider

$$
\begin{gathered}
\sum_{G} X_{i j}(\text { it })-\sum_{G} X_{j i}(\text { it })= \begin{cases}-1 & \text { if } j=\text { origin } \\
1 & \text { if } j=\text { destination } \\
0 & \text { otherwise }\end{cases} \\
\forall \text { it }=2,3, \ldots, \text { number of chaos iterations. }
\end{gathered}
$$

In intercity transportation mode, two-way edges are usually available, so (5) is inserted in mathematical model to provide the above characteristics [26]. For more details on developing mathematical model in the case of hazmat routing problem, please refer to $[24,26]$. Consider

$$
(i, j),(j, i) \in G \text { in all chaos iterations. }
$$

Mathematical model is being run until the number of simulation iterations is met; then the most frequent edges will be ranked in terms of their usages. Chaotic iteration is set to 365 while simulation iteration is set to 1000 and 500 for sensitivity analysis, so the whole iteration numbers will be set to 365000 for running the model and 182500 for sensitivity analysis.

\section{Case Study}

Fars, the second largest province in the Asian country of Iran, is selected as case study whose map is available on [27]. It consists of fifty-nine nodes and eighty two-way edges. Some of nodes are considered as border, which connect research area to other provinces. For each link, risk is calculated based on four components of accident, environment, population, and infrastructure aspects. Cost is corresponding to the length and travel time obtained by a research survey [24].

\section{Running Model and Discussion}

Running the model is one of the most important stages of this research work. At the first step, a clear definition on problem is defined in which more details on problem are discussed. At the second step, five scenarios are defined using different priorities for risk and cost in hazmat transportation. 
TABLE 1: List of origin and destination nodes (dimension = thousands $\mathrm{M}^{3}$ per year).

\begin{tabular}{|c|c|c|c|c|c|c|c|c|c|c|c|c|c|}
\hline \multirow{2}{*}{ Origin } & \multicolumn{13}{|c|}{ Destination nodes } \\
\hline & $\{2\}$ & $\{11\}$ & $\{13\}$ & $\{15\}$ & $\{17\}$ & $\{23\}$ & $\{32\}$ & $\{35\}$ & $\{40\}$ & $\{42\}$ & $\{45\}$ & $\{56\}$ & Sum \\
\hline$\{13\}$ & & 150 & 650 & & & & & 300 & & & 500 & & 1600 \\
\hline$\{14\}$ & & 150 & & 500 & 550 & 400 & & & & & & & 1600 \\
\hline$\{26\}$ & 100 & & & & & & 400 & & 500 & & & 500 & 1500 \\
\hline$\{38\}$ & & & & & & & 300 & 350 & 400 & 450 & & & 1500 \\
\hline$\{55\}$ & 300 & 400 & & & 300 & & & & & & & 400 & 1400 \\
\hline Sum & 400 & 700 & 650 & 500 & 850 & 400 & 700 & 650 & 900 & 450 & 500 & 900 & 7600 \\
\hline
\end{tabular}

TABLE 2: Risk and cost priorities scenarios.

\begin{tabular}{lcc}
\hline Scenario & \multicolumn{2}{c}{ Priorities } \\
& Risk & Cost \\
\hline A1 & $0.0(0 \%)$ & $1.0(100 \%)$ \\
A2 & $0.3(30 \%)$ & $0.7(70 \%)$ \\
A3 & $0.5(50 \%)$ & $0.5(50 \%)$ \\
A4 & $0.7(70 \%)$ & $0.3(30 \%)$ \\
A5 & $1.0(100 \%)$ & $0.0(0 \%)$ \\
\hline
\end{tabular}

The above scenarios are followed by numerical results which reveal the finding of the research work. Sensitivity analysis at the final stage is also applied for readers to make sure that decision makers do not have to worry about using chaos theory concept in the proposed procedure even there is a noticeable consideration of having dependency upon initial condition in chaos theory.

6.1. Details on Problem Definition. Sets of origins and destinations have been determined to solve the proposed procedure and developed model. According to case study, five nodes are identified as origin nodes and twelve nodes as destination nodes, shown in Table 1; those names are explained in Table 5. The amount of hazmat planned to be carried form origins to destinations is identified using the scales of heavy trucks.

6.2. Scenarios. According to problem definition and proposed procedure, risk and cost priorities have significant influences on solving the problem to determine paths and consequent results. In order to satisfy decision makers who are dealing with planning on hazmat transportation and cover a wide range of risk and cost priorities, the most probable sets are of risk and cost priorities defined by five scenarios and shown in Table 2. Risk and cost priorities are defined as $P_{r}$ and $P_{c}$ in mathematical model, respectively.

6.3. Numerical Results. Due to lack of constructive and maintenance budget for improving the road safety network, using a high selected list of links, in the above network, would be a good approach for planning safety programs. Therefore, links which have been frequently selected in simulation process should be nominated for improving road construction. On the other hand, decision makers' points of view are different in terms of the amount of risk and cost priorities. The proposed methodology and developed mathematical model have been performed using five scenarios, defined in the previous section, and high frequent links have been obtained from the execution process. Results which show the most frequent links selected for hazardous materials transportation have been tabulated in Table 3. For each scenario, a ranked order of edges which are most frequently used for hazmat transportation is proposed. Ranking is provided according to the number of usages in path finding regarding the number of iterations. For example, if decision makers set risk and cost priorities to 0.3 and 0.7 , respectively, links $(14,15),(15,16)$, and $(13,14)$ will be selected as high ranked priority for improving road construction. But if the priority of risk goes up, link (13, 14) will be substituted by $(37,38)$ which means that using the different priorities for risk and cost changes the order of selected links.

Results also revealed that the orders of high frequent links using different scenarios are different, due to the existing differences between risk and cost priorities. In order to make a whole consideration on using a wide range of cost and risk priorities, the most repeated links are also outlined in the last column of Table 3. The last column helps decision makers to get a final solution, even if they cannot reach to the final decision on how much the cost and risk priorities may be set. Therefore, according to author's experiences, it is recommended that decision makers use the last column of Table 3 to improve road safety measures, because a wide range of risk and cost priorities have been considered for running the proposed methodology.

6.4. Sensitivity Analysis. Chaos theory is commonly applied for short-term prediction due to the existence of property of "sensitive dependence upon initial condition." Initial condition may dramatically change the results of finding safest path after some iteration, and it may be questioned whether process is suitable for long-term decision-making or not [19]. In fact, initial seeds change the results in different iterations [24], so sensitivity analysis, here, is to check results using different initial seeds [24]. In order to check the reliability of the proposed method, five initial seeds have been used 
TABLE 3: List of ten top ranked edges for different scenarios.

\begin{tabular}{|c|c|c|c|c|c|c|}
\hline \multirow{2}{*}{ Ranking } & \multicolumn{5}{|c|}{ Scenarios } & \multirow{2}{*}{ Most repeated } \\
\hline & $\mathrm{A} 1$ & A2 & A3 & A4 & A5 & \\
\hline 1 & $(14,15)$ & $(14,15)$ & $(14,15)$ & $(14,15)$ & $(14,15)$ & $(14,15)$ \\
\hline 2 & $(15,16)$ & $(15,16)$ & $(15,16)$ & $(15,16)$ & $(15,16)$ & $(15,16)$ \\
\hline 3 & $(26,27)$ & $(13,14)$ & $(13,14)$ & $(37,38)$ & $(37,38)$ & $(37,38)$ \\
\hline 4 & $(16,17)$ & $(37,38)$ & $(37,38)$ & $(26,27)$ & $(26,27)$ & $(26,27)$ \\
\hline 5 & $(13,14)$ & $(26,27)$ & $(26,27)$ & $(13,14)$ & $(54,55)$ & $(26,27)$ \\
\hline 6 & $(37,38)$ & $(38,42)$ & $(54,55)$ & $(54,55)$ & $(27,28)$ & $(54,55)$ \\
\hline 7 & $(38,42)$ & $(16,17)$ & $(27,28)$ & $(27,28)$ & $(28,30)$ & $(27,28)$ \\
\hline 8 & $(3,55)$ & $(54,55)$ & $(28,30)$ & $(28,30)$ & $(38,42)$ & $(28,30)$ \\
\hline 9 & $(35,59)$ & $(27,28)$ & $(16,17)$ & $(38,42)$ & $(13,46)$ & $(16,17)$ \\
\hline 10 & $(36,59)$ & $(28,30)$ & $(38,42)$ & $(16,17)$ & $(13,14)$ & $(38,42)$ \\
\hline
\end{tabular}

The number of iterations for each scenario $=365000$.

TABLE 4: List of ten top ranked edges for scenario (A3).

\begin{tabular}{|c|c|c|c|c|c|c|}
\hline \multirow{2}{*}{ Ranking } & \multicolumn{6}{|c|}{ Seed } \\
\hline & 50 & 100 & 250 & 500 & 1000 & Most frequent \\
\hline 1 & $(14,15)$ & $(14,15)$ & $(14,15)$ & $(14,15)$ & $(14,15)$ & $(14,15)$ \\
\hline 2 & $(15,16)$ & $(15,16)$ & $(15,16)$ & $(15,16)$ & $(15,16)$ & $(15,16)$ \\
\hline 3 & $(13,14)$ & $(13,14)$ & $(13,14)$ & $(13,14)$ & $(13,14)$ & $(13,14)$ \\
\hline 4 & $(37,38)$ & $(37,38)$ & $(37,38)$ & $(37,38)$ & $(37,38)$ & $(37,38)$ \\
\hline 5 & $(26,27)$ & $(26,27)$ & $(26,27)$ & $(26,27)$ & $(26,27)$ & $(26,27)$ \\
\hline 6 & $(54,55)$ & $(54,55)$ & $(54,55)$ & $(54,55)$ & $(54,55)$ & $(54,55)$ \\
\hline 7 & $(27,28)$ & $(16,17)$ & $(16,17)$ & $(27,28)$ & $(27,28)$ & $(27,28)$ \\
\hline 8 & $(28,30)$ & $(27,28)$ & $(27,28)$ & $(28,30)$ & $(28,30)$ & $(28,30)$ \\
\hline 9 & $(16,17)$ & $(28,30)$ & $(28,30)$ & $(38,42)$ & $(16,17)$ & $(16,17)$ \\
\hline 10 & $(38,42)$ & $(38,42)$ & $(38,42)$ & $(16,17)$ & $(38,42)$ & $(38,42)$ \\
\hline
\end{tabular}

The number of iterations for each scenario using each seed $=182500$.

for generating random risk factors. Although there is no difference between the defied scenarios, scenario 3, in which the risk and cost priorities are the same (50\%, 50\%), has been checked as just a sample in which a ranked order of edges has been outlined and shown in Table 4 . Since it is possible to check the other scenarios, the above scenario has been selected due to the common decision of policy makers which usually set the equal rates for risk and cost priorities. Results show that there is no significant difference between ranked links using different seeds. Therefore, it is fair to say that the proposed methodology is capable of being used for ranking the edges which have been frequently used to improve road safety quality for hazmat transportation.

\section{Summary and Conclusion}

One of the most popular approaches for determining routes for hazmat transportation is to set a predefined road network. The safest path for hazardous material transportation is generally determined by minimizing risk and cost for specified origins and destinations. In this situation, improving the edges which are frequently used for carrying hazardous material might be a good concept for decreasing total risk over the network. On the other hand, risk is a chaotic variable used for hazmat routing problem and is changed during a time period.

In order to make a high selected list of network edges, which are frequently used for hazmat transportation, a chaotic-simulated model has been developed. Risk factors over the network are generated using the simulation technique and updated during the iteration using the well-known equation of logistic map. An experimental road network consists of fifty-nine nodes and eighty edges which have been used for analytical process and sensitivity analysis is also checked to ensure that using the proposed methodology is appropriate. While numerical results show that the ranking of edges may be different using risk and cost priorities, sensitivity analysis shows that there is no significant difference between outlined ranking orders using different seeds. 
TABLE 5: List of nodes and their names in road network located in the Iranian province of Fars.

\begin{tabular}{|c|c|}
\hline Code & Name \\
\hline 1 & Izadkhast \\
\hline 2 & Abadeh \\
\hline 3 & Sormagh \\
\hline 4 & Safashahr \\
\hline 5 & Bavanat \\
\hline 6 & Sarvestan \\
\hline 7 & Saadat Shahr \\
\hline 8 & Arsanjan \\
\hline 9 & Naqsh-e Rostam \\
\hline 10 & Jamalabad \\
\hline 11 & Marvdasht \\
\hline 12 & Soltanabad \\
\hline 13 & Shiraz \\
\hline 14 & Polefasa \\
\hline 15 & Estahban \\
\hline 16 & Dorahi Estahban and Fasa \\
\hline 17 & Fasa \\
\hline 18 & Shahrood \\
\hline 19 & Fadshokoieh \\
\hline 20 & Chaliyan \\
\hline 21 & Dindarlo \\
\hline 22 & Ghaleh ab barik \\
\hline 23 & Neyriz \\
\hline 24 & Sirjan \\
\hline 25 & Ich \\
\hline 26 & Darab \\
\hline 27 & Dowlatabad \\
\hline 28 & Khosravi \\
\hline 29 & Hajiabad \\
\hline 30 & Dorahi Lar Jahrom \\
\hline 31 & Mansoorabad \\
\hline 32 & Lar \\
\hline 33 & Bandar Abbas \\
\hline 34 & Evaz \\
\hline 35 & Lamerd \\
\hline 36 & Chah Eyni \\
\hline 37 & Khonj \\
\hline 38 & Qirokarzin \\
\hline 39 & Simakan \\
\hline 40 & Jahrom \\
\hline 41 & Qotbabad \\
\hline 42 & Firuzabad \\
\hline 43 & Esmaeil Abad \\
\hline 44 & Fathabad \\
\hline 45 & Kazerun \\
\hline 46 & Dashteharzhan \\
\hline 47 & Bazargan \\
\hline 48 & Konartakhteh \\
\hline 49 & Qaemiyeh \\
\hline
\end{tabular}

TABLE 5: Continued.

\begin{tabular}{lc}
\hline Code & Name \\
\hline 50 & Noor Abad \\
51 & Serahi Noor Abad, Sepidan, and Shiraz \\
52 & Masiri \\
53 & Koshk \\
54 & Asias \\
55 & Eqlid \\
56 & Sepidan \\
57 & Yasooj \\
58 & Forg \\
59 & Dehno \\
\hline
\end{tabular}

\section{Conflict of Interests}

This research work has been done using data gathered for carrying out author's Ph.D. thesis and it is claimed that no funding or financial support from fellowship, scholarship, or any sponsors has been gained by the author. Therefore the author declares that there is no conflict of interests regarding the publication of this paper.

\section{References}

[1] Environmental Health \& Safety, Hazardous Material Classification, NC State University, 2011, http://www.ncsu.edu/ehs/ dot/classification.html.

[2] K. G. Zografos and K. N. Androutsopoulos, "A heuristic algorithm for solving hazardous materials distribution problems," European Journal of Operational Research, vol. 152, no. 2, pp. 507-519, 2004.

[3] J. M. Díaz-Báñez, F. Gómez, and G. T. Toussaint, “Computing shortest paths for transportation of hazardous materials in continuous spaces," Journal of Food Engineering, vol. 70, no. 3, pp. 293-298, 2005.

[4] E. Erkut and O. Alp, "Designing a road network for hazardous materials shipments," Computers and Operations Research, vol. 34, no. 5, pp. 1389-1405, 2007.

[5] S. Bonvicini and G. Spadoni, "A hazmat multi-commodity routing model satisfying risk criteria: a case study," Journal of Loss Prevention in the Process Industries, vol. 21, no. 4, pp. 345358, 2008.

[6] A. S. Mohaymany and M. Khodadadian, "A routing methodology for hazardous material transportation to reduce the risk of road network," International Journal of Engineering Science, vol. 19, no. 3, pp. 57-65, 2008.

[7] J. Banks, J. Carson, B. Nelson, and D. Nicol, Discrete-Event System Simulation, Prentice Hall, 2001.

[8] National Science Foundation (NSF) Blue Ribbon Panel, Report on Simulation-Based Engineering Science: Revolutionizing Engineering Science through Simulation, NSF Press, 2006.

[9] S. Sundaram, H. N. Koutsopoulos, M. Ben-Akiva, C. Antoniou, and R. Balakrishna, "Simulation-based dynamic traffic assignment for short-term planning applications," Simulation Modelling Practice and Theory, vol. 19, no. 1, pp. 450-462, 2011.

[10] A. Sobhani, W. Young, and M. Sarvi, "A simulation based approach to assess the safety performance of road locations," 
Transportation Research C: Emerging Technologies, vol. 32, pp. 144-158, 2013.

[11] C. Caliendo, P. Ciambelli, M. L. D. Guglielmo, M. G. Meo, and P. Russo, "Numerical simulation of different HGV fire scenarios in curved bi-directional road tunnels and safety evaluation," Tunnelling and Underground Space Technology, vol. 31, pp. 3350, 2012.

[12] X. Ma and I. Andréasson, "Predicting the effect of various ISA penetration grades on pedestrian safety by simulation," Accident Analysis and Prevention, vol. 37, no. 6, pp. 1162-1169, 2005.

[13] J. S. Stine, B. C. Hamblin, S. N. Brennan, and E. T. Donnell, "Analyzing the influence of median cross-section design on highway safety using vehicle dynamics simulations," Accident Analysis and Prevention, vol. 42, no. 6, pp. 1769-1777, 2010.

[14] A. Cartenì and S. D. Luca, "Tactical and strategic planning for a container terminal: modelling issues within a discrete event simulation approach," Simulation Modelling Practice and Theory, vol. 21, no. 1, pp. 123-145, 2012.

[15] J. S. Yeomans, "Solid waste planning under uncertainty using evolutionary simulation-optimization," Socio-Economic Planning Sciences, vol. 41, no. 1, pp. 38-60, 2007.

[16] A. Athanasenas, "Traffic simulation models for rural road network management," Transportation Research E: Logistics and Transportation Review, vol. 33, no. 3, pp. 233-243, 1997.

[17] H. K. Dehnavi, M. T. Rezvan, A. Shirmohammadli, and D. Vallée, "A solution for urban road selection and construction problem using simulation and goal programming-case study of the city of Isfahan," Transport Policy, vol. 29, pp. 46-53, 2013.

[18] G. James, Chaos: Making a New Science, 1987.

[19] W. L. Lawrence, Y. L. Feng, and Y. C. Huang, "Diagnosis of freeway traffic incidents with chaos theory," Journal of the Eastern Asia Society for Transportation Studies, vol. 5, pp. 20252038, 2003.

[20] J. Mingjun and T. Huanwen, "Application of chaos in simulated annealing," Chaos, Solitons and Fractals, vol. 21, no. 4, pp. 933941, 2004.

[21] C. Frazier and K. M. Kockelman, "Chaos theory and transportation systems: instructive example," Transportation Research Record, no. 1897, pp. 9-17, 2004.

[22] G. Sugihara and R. M. May, "Nonlinear forecasting as a way of distinguishing chaos from measurement error in time series," Nature, vol. 344, no. 6268, pp. 734-741, 1990.

[23] A. Mahmoudabadi and S. M. Seyedhosseini, "Application of chaos theory in hazardous material transportation," International Journal of Transportation Engineering, vol. 1, no. 1, pp. 1523, 2012.

[24] A. Mahmoudabadi and S. M. Seyedhosseini, "Developing a chaotic pattern of hazmat routing problem," IATSS Research, vol. 37, no. 2, pp. 110-118, 2014.

[25] L. D. Kiel and E. Elliott, Chaos Theory in the Social Sciences, Foundations and Applications, University of Michigan, 1996.

[26] E. Erkut and F. Gzara, "Solving the hazmat transport network design problem," Computers and Operations Research, vol. 35, no. 7, pp. 2234-2247, 2008.

[27] A. Mahmoudabadi and S. M. Seyedhosseini, "Improving the efficiency of weigh in motion systems through optimized allocating truck checking oriented procedure," IATSS Research, vol. 36, no. 2, pp. 123-128, 2013. 

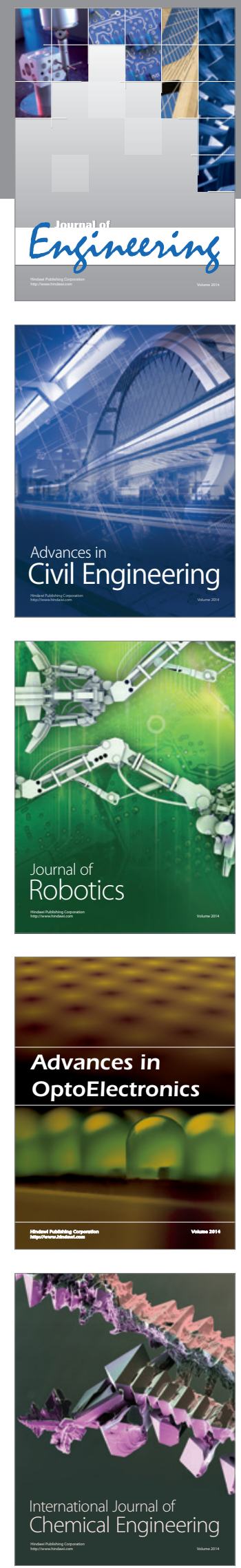

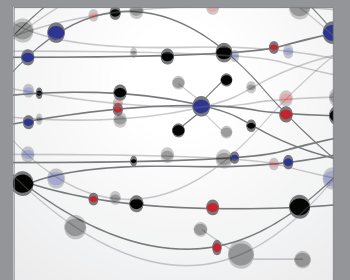

The Scientific World Journal
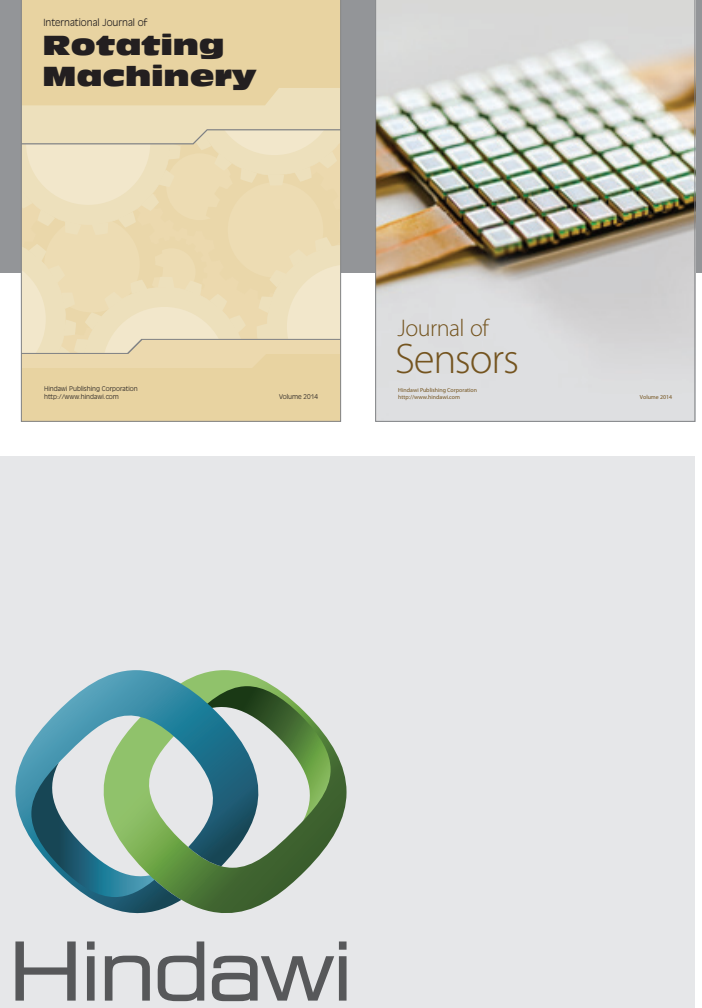

Submit your manuscripts at http://www.hindawi.com

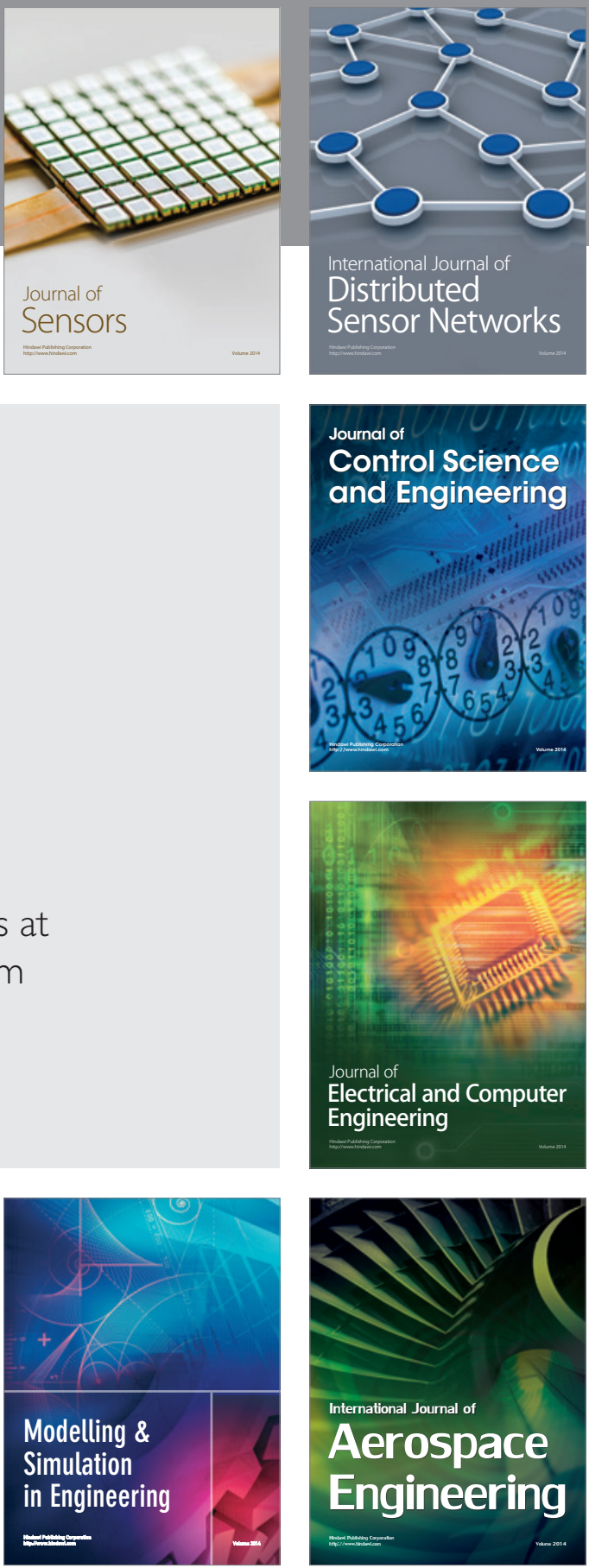

Journal of

Control Science

and Engineering
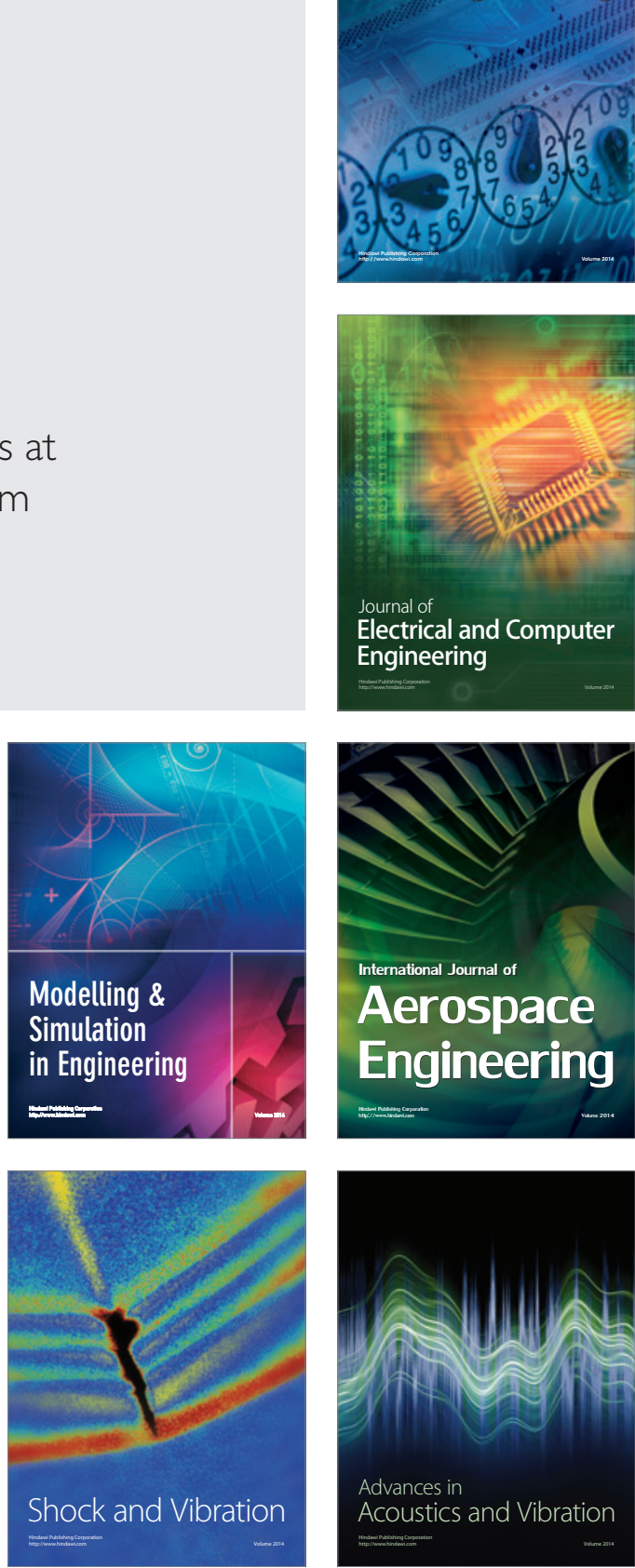